\title{
Erratum to: Identification and Validation of Risk Factors for Postoperative Infectious Complications Following Hepatectomy
}

\author{
Patrick Pessaux • Maartje A. J. van den Broek • Tao Wu • \\ Steven W. M. Olde Damink • Tullio Piardi • Cornelis H. C. Dejong • \\ Dimitrios Ntourakis • Ronald M. van Dam
}

Published online: 25 September 2013

(C) 2013 The Society for Surgery of the Alimentary Tract

\section{Erratum to: J Gastrointest Surg \\ DOI 10.1007/s11605-013-2226-1}

Erratum to "Identification and validation of risk factors for postoperative infectious complications following hepatectomy" co-authored by P. Pessaux et al published on line in the Journal of Gastrointestinal Surgery on May 10, 2013.

We the authors of the above article failed to site in our reference list a previous publication by one of the co-authors that merited citation. That citation is: "Multivariate anlysis of risk factors for pulmonary complications after hepatic resection” authored by Nobili C, Marzano E, Oussoultzoglou E, Rosso E, Addeo P, Bachellier P, Jaeck D and Pessaux P. Ann Surg 225:540-550, 2012.

We the authors would like to correctly attribute the data in our JOGS publication, recognizing that these data were

The online version of the original article can be found at http://dx.doi.org/ 10.1007/s11605-013-2226-1.

P. Pessaux $(\bowtie) \cdot$ T. Piardi $\cdot$ D. Ntourakis

Department of Hepato-Biliary and Pancreatic Surgery, Nouvel

Hopital Civil, Université de Strasbourg, IHU MixSurg,

IRCAD, 1 place de l'hôpital, 67091 Strasbourg, France

e-mail: patrick.pessaux@chru-strasbourg.fr

M. A. J. van den Broek · S. W. M. O. Damink • C. H. C. Dejong

R. M. van Dam

Department of Surgery and NUTRIM, School for Nutrition,

Toxicology and Metabolism, Maastricht University Medical Centre,

Maastricht, The Netherlands

T. Wu

Department of Hepato-Biliary and Pancreatic Surgery, University

Hospital N², University of Kunming, 374 street Dianmian,

Kunming 650101, China

S. W. M. O. Damink

Department of Hepatopancreatobiliary Surgery and Liver

Transplantation, Royal Free Hospital, London, UK retrieved, captured and analyzed from patients at the Hospital de Hautepierre.

The correct author affiliations for four of the authors of the JOGS article are listed below:

TAO WU and PATRICK PESSAUX: Service de Chirurgie Générale, Hépatique et Endocrinienne, Pole des Pathologies Digestives, Hépatiques et de la Transplantation, Hopital de Hautepierre, Hôpitaux Universitaires de Strasbourg, Université de Strasbourg, Avenue Moliere, 67098 Strasbourg, France

TULLIO PIARDI and DIMITRIOS NTOURAKIS: Service de Chirurgie Generale et Transplantation Multiogane, Pole des Pathologies Digesives, Hepatiques et de la Transplantation, hôpital de Hautepierre, Hopitaux Universitaires de Strasbourg, Avenue Moliere 667098 Strasbourg, France. 